\title{
XX Aniversario Instituto Martin Luther King, UPOLI
}

Denis Torres

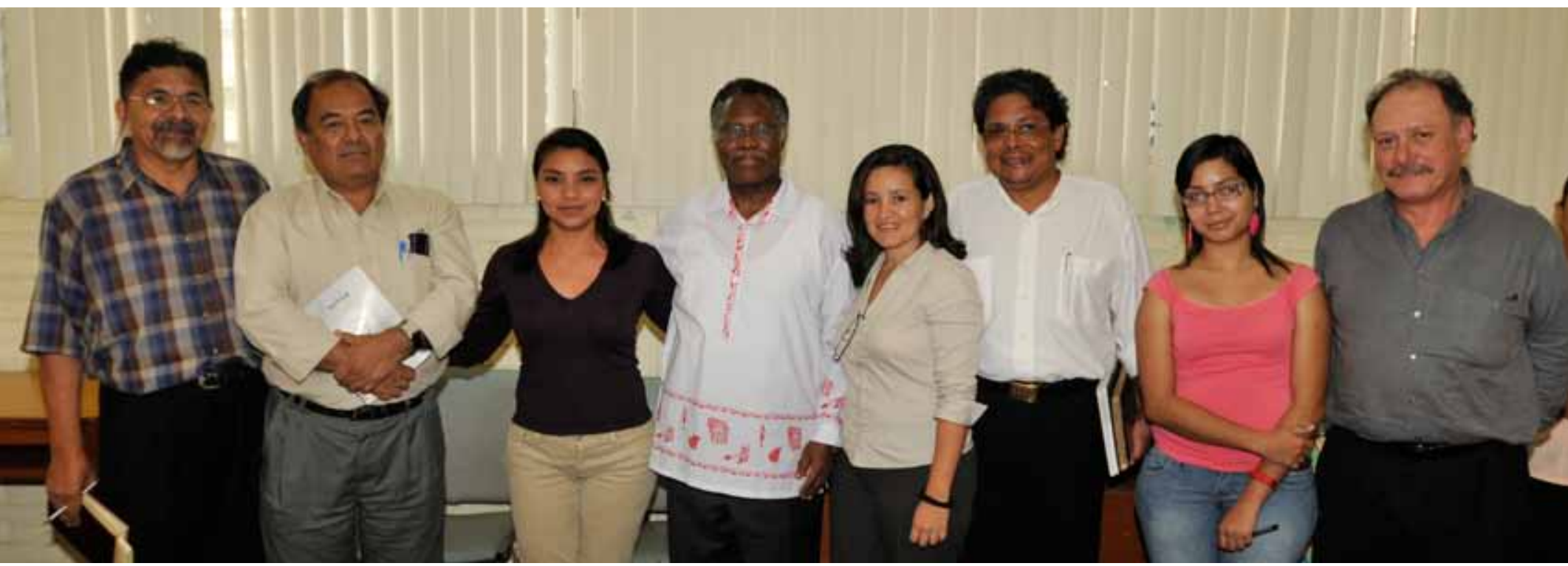

$\mathrm{E}$ ste año 2013 es el año del XX aniversario del Instituto de Investigaciones y acción social "Martin Luther King" de la universidad Politécnica de Nicaragua UPOLI. Fue fundado en 1993, cuando Nicaragua venia saliendo de una larga guerra, cruenta y devastadora, que inició como guerra de agresión (así la definió la CIJ) pero que devino guerra civil, es decir fue fundado en un período cuando se vivía todas las secuelas de aquella confrontación fratricida: división y polarización profunda de nuestra sociedad, ánimos de venganza, fenómenos de re armamiento, intentos de eliminación del Otro.

En este contexto, complejo y difícil, la UPOLI crea al Instituto Martin Luther King. Se corresponde reconocer la visión de las autoridades universitarias de entonces, que acogieron, estimularon y se comprometieron con aquella iniciativa novedosa, pertinente, única en nuestra historia regional.

Se trataba de levantar, divulgar, diseminar, proponer la creación de un nuevo paradigma, la Cultura de Paz, que cambiara el curso de una historia ensangrentada, excluyente y de profundas desigualdades sociales, que superara toda una cultura de violencia que ha moldeado nuestro ser nacional y que ha estado en la base de nuestro atraso secular.

La UPOLI se transformó así en una universidad de anticipación, pionera, forjadora, incorporando la Cultura de Paz en parte consustancial de su Misión y Visión. De allí que la creación del Instituto Martin Luther King fue la expresión de la institucionalización de esa voluntad y compromiso con la Cultura de Paz. Organismos

* Ex Director General de la UNESCO y Presidente de la Fundación Cultura de Paz. 
mundiales han llamado la atención sobre este hecho y el que su órgano de comunicación por excelencia, la Revista Cultura de Paz lleve ese nombre, único caso en el mundo.

Son la investigación, la educación, capacitación, extensión e incidencia nacional e internacional los ámbitos naturales desde donde actúa el Instituto Martin Luther King en tanto entidad académica. Recuperación de la memoria histórica, experiencias constructoras de paz y reconciliación de nuestro pueblo; diseños e implementación de curriculum de Cultura de Paz, programas nacionales de educación para la paz dirigidos a distintos actores sociales: medios de comunicación, poblaciones originarias, iglesia, policía, jóvenes, mujeres, educadores; la sistematización y difusión del pensamiento de la cultura de paz a través del Sello Editorial NOS OTROS con la publicación de 42 obras relacionadas y de la Revista Cultura de Paz con la edición de 60 números ininterrumpidos a lo largo de 19 años y que circula en tres directorios internacionales; el acompañamiento, colaboración y solidaridad de un conjunto de relevantes pensadores mundiales y nacionales de diversas disciplinas; iniciativas de paz y reconciliación nacionales, regionales y mundiales, son líneas de trabajo que han contribuido a sensibilizar, conocer e iniciar un proceso de apropiación de este nuevo paradigma en Nicaragua y el mundo.

Vale la pena recordar que fue el Instituto Martin Luther King de la UPOLI quien en medio de sus condiciones materiales limitadas en que desarrolla su trabajo toco por vez primera la conciencia de la humanidad para fijar su atención sobre el paradigma de la reconciliación -tema crucial para alcanzar una paz duradera en los momentos que vive el mundo- promoviendo en la Asamblea General de Naciones Unidas declararan el año 2009 como Año Internacional de Reconciliación, la cual desencadeno acciones e iniciativas de perdón y reconciliación entre estados del mundo y al interior de comunidades nacionales, construyéndose para en referencia para el futuro e incorporándose al lenguaje y praxis de la comunidad internacional organizada.

Sin embargo, todo cambio cultural en una sociedad y en el mundo lleva su tiempo. Es lo que ha pasado con los paradigmas de los derechos humanos que hasta hace apenas dos o tres generaciones eran consideradas una utopía, algo inalcanzable, pero ahora son parte de una nueva cultura, lucha, derecho, vivencia, ampliación a nuevos ámbitos de nuestras vidas, incluso sentido común, pasaron varias décadas para que se institucionalizaran e interiorizaran. Es lo que se ha venido dando con el paradigma del medio ambiente y ahora con la Cultura de Paz.

El paso de una cultura de violencia a una cultura de paz es una tarea de todos, en la cual interactúan los actores de una sociedad, ello demanda de los gobiernos voluntad política, leyes, instituciones, un sistema educativo que incorpore en sus contenidos los, valores, conocimientos, principios y habilidades, propios del nuevo paradigma; un compromiso de las entidades que inciden en la forjación de mentalidades y comportamiento social.

Nicaragua viene experimentando logros en esta dirección, aunque no con la rapidez y el vigor necesario, perceptible entre otros, en el alejamiento cada vez mayor de la violencia política para dirimir las diferencias, la clase política nicaragüense ha expresado un compromiso explicito para realizar sus acciones transformadoras o de relevo en el poder, por medios pacíficos que no comprometen la siempre precaria paz que hoy gozamos, un nuevo lenguaje, leyes particulares como la ley integral contra la violencia hacia las mujeres, el Código de la Niñez y la Adolescencia, ley de enseñanza obligatoria de los derechos humanos, la creación de algunas instituciones como la Procuraduría Para la Defensa de los Derechos Humanos.

La apropiación por algunas universidades, y ONG's del paradigma de la Cultura de Paz, organizaciones de la sociedad civil para la defensa y protección del medio ambiente, de prevención de la violencia de defensa y promoción de los derechos de la mujer, organizaciones de derechos humanos, organismos para el desarrollo de la democracia.

Llegamos a estos 20 años, con la convicción de que estamos en el camino hacia una Cultura de Paz, de que nuestro modesto aporte pionero queda ya como anticipo que tendrá el futuro, como referencia de una historia que está por escribirse, la historia de la Cultura de Paz.

MSc. Denis Torres.

Director IMLK 